\title{
Addition of Fillers to Sodium Alginate Solution Improves Stability and Immobilization Capacity of the Resulting Calcium Alginate Beads
}

\author{
Uchenna Oyeagu ${ }^{1}$, Charles O. Nwuche ${ }^{1}$, Christiana N. Ogbonna ${ }^{2}$, James C. Ogbonna ${ }^{1 *}$ \\ ${ }^{1}$ Department of Microbiology, University of Nigeria Nsukka, Nsukka, Enugu State, Nigeria \\ ${ }^{2}$ Department of Plant Science and Biotechnology, University of Nigeria, Nsukka, Enugu State, Nigeria
}

\begin{abstract}
"Corresponding author: James C. Ogbonna, Department of Microbiology, University of Nigeria Nsukka, Nsukka, Enugu State, Nigeria Tel: +2348037136810; E-mail: james.ogbonna@unn.edu.ng

Received: 7 Feb. 2017; $\quad$ Revised: 31 Jan. 2018; Accepted: 5 Mar. 2018; Published online: 18 Apr. 2018
\end{abstract}

\begin{abstract}
Background: Although advantages of immobilization of cells through entrapment in calcium alginate gel beads have already been demonstrated, nevertheless, instability of the beads and the mass transfer limitations remain as the major challenges. Objective: The objective of the present study was to increase the stability, porosity (reduce mass transfer limitation), and cell immobilization capacity of calcium alginate gel beads.

Materials and Methods: Sodium alginate was mixed with various concentrations of the starch or sugar and gelled in $2 \%$ calcium chloride solution. During the gelling and curing, the starch or sugar leached out of the beads and created micropores.

Results: Micro-porous beads prepared with starch were more stable and had higher immobilization capacity than those prepared with sugar. After 24 hours of incubation (curing) of the micro-porous beads prepared with starch in calcium alginate, the solubilization time in citrate buffer was 93 minutes compared to 41 minutes for the control beads (without starch). The compressive strength of the micro-porous beads was also higher (5.62 Mpa) than that of the control beads (5.54 Mpa). The optimal starch concentration for cell immobilization was $0.4 \%$. With this starch concentration, the immobilized Bacillus subtilis and Saccharomyces cerevisiae cell densities were $5.6 \times 10^{9}$ and $1.2 \times 10^{8}$ cells/beads, respectively. These values were $36.5 \%$ and $74 \%$ higher than the value obtained for the control beads. This method of immobilization resulted in more uniform cell distribution.

Conclusion: Addition of starch to the sodium alginate solution before gelation in calcium chloride solution increased the stability of the beads, increased the immobilized cell density, and resulted in a more uniform cell distribution in the beads.

Keywords: Bacillus subtilis, Calcium alginate beads, Cell immobilization, Mass transfer, Micro-porous gel beads, Saccharomyces cerevisiae
\end{abstract}

\section{Background}

A number of major problems limiting the industrial application of cells immobilized in calcium alginate gel beads include chemical and physical instability of the beads in addition to mass transfer limitation. The beads are easily disintegrated by high hydrodynamic stress and solubilized easily in a medium containing high concentrations of citrate, phosphate, and other chelating agents. Furthermore, depending on the size of the beads, immobilized cells grow preferentially at the periphery of the beads due to mass transfer limitation $(1,2)$. Several approaches have been investigated as possible solutions to mass transfer problems. Tanaka et al., (3) and, Tartakovsky et al., (4) have proposed co-immobilization of the aerobic and anaerobic cells. In such systems, there is niche segregation so that the aerobic cells grow mainly in the periphery of the bead while the anaerobic cells grow mainly in the core of the beads. However, this method is only applicable to the mixed culture systems involving aerobic and anaerobic microorganisms. Reduction of the beads' diameter through atomization of the sodium alginate is another proposed method for reducing mass transfer limitation in the gel beads

Copyright (C) 2017 The Author(s); Published by National Institute of Genetic Engineering and Biotechnology. This is an open access article, distributed under the terms of the Creative Commons Attribution-NonCommercial 4.0 International License (http://creativecommons.org/licenses/ by-nc/4.0/) which permits others to copy and redistribute material just in noncommercial usages, provided the original work is properly cited. 
(5). Unfortunately, micro-gel bead production is expensive and production of large quantity of the beads is technically challenging. Kregiel et al., (6) have entrapped cells in foamed alginate beads, and the application of such immobilization system in the fermentation of fruit pomaces have been investigated (7). Although cells grew well within the foamed beads, the beads showed poor stability and evolution of the high concentration of carbon dioxide resulted in the rupture of the beads. Improving the stability of the beads could be achieved by using strontium chloride as the gelling agent (8), using media that do not contain chelating agents, or by addition of gelling agents to the fermentation medium.

\section{Objective}

The aim of the present investigation is to improve the stability of the beads and reduce mass transfer limitation by gelling a mixture of sodium alginate and fillers, which are subsequently leached out during the incubation in the calcium chloride, thereby increasing the porosity of the beads.

\section{Materials and Methods}

\subsection{Preparation of Microbial Inoculum}

Saccharomyces cerevisiae IR-2 (9), and Bacillus subtilis (ATCC 35021) were used in this study. S. cerevisiae was activated in a chloramphenicol-supplemented YPG liquid medium containing (in g. $\mathrm{L}^{-1}$ ): glucose, 10; yeast extract, 3; peptone, 5 and chloramphenicol, 0.05 . Three loopful of the slant was inoculated into a $50 \mathrm{~mL}$ of broth medium and incubated at $28 \pm 2{ }^{\circ} \mathrm{C}$ for $72 \mathrm{~h}$. The Bacillus subtilis (ATCC 35021) strain was activated in a nutrient broth for $48 \mathrm{~h}$. In each case, after cultivation, the broth was centrifuged at $5000 \mathrm{~g}$ for 5 minutes, the supernatant was discarded while the pellet containing the cells was washed twice in sterile physiological saline $(0.85 \% \mathrm{NaCl})$ and then with distilled water before using for cell immobilization studies. All the media, reagents and chemicals used in the present study were reagent grade and purchased from Wako Chemicals Osaka, Japan.

\subsection{Cell Immobilization in Normal Calcium Alginate Gel Beads}

A $2 \%(\mathrm{w} / \mathrm{v})$ sodium alginate solution was prepared, autoclaved at $121{ }^{\circ} \mathrm{C}$ for 15 minutes and cooled down to $28 \pm 2{ }^{\circ} \mathrm{C}$ before mixing with the cell suspension. The cell density in the inoculum was determined by counting with the improved Neubeur haemacytometer and diluted to obtain the desired cell concentration.
The mixture was dropped slowly using a micropipette into a gently stirred ( $70 \mathrm{rpm}) 2 \% \mathrm{CaCl}_{2} \cdot 2 \mathrm{H}_{2} \mathrm{O}$ solution under a magnetic stirrer (OP-912/3 Radelkis, Hungary). The alginate droplets were solidified upon contact with calcium chloride solution, forming beads. The resulting calcium alginate gel beads were incubated in the same magnetically stirred $\mathrm{CaCl}_{2} \cdot 2 \mathrm{H}_{2} \mathrm{O}$ solution for $24 \mathrm{~h}$ for cross-linking (curing) and stability under aseptic conditions. The beads were recovered and washed in a sterile distilled water to remove excess calcium ion and un-entrapped cells before introduction into the fermentation flask.

\subsection{Production of Micro-Porous Beads}

Sodium alginate was mixed with different concentrations (between 0.4 and $4.0 \%$ ) of the filler [ $\operatorname{starch}(\mathrm{St})$ or granulated sugars $(\mathrm{Gs})]$ and the mixtures were autoclaved as described before. The mixture was then dropped into a gently stirred calcium chloride solution. Since there is no cross-linking between alginate and starch or alginate and sugar, both the $\mathrm{St}$ and Gs leached out of the beads during incubation in $\mathrm{CaCl}_{2}$ solution. This created micro-pores in the beads. The measured diameter of the micro pores in the gel beads was ranging from 10 to $500 \mathrm{~nm}$ when Gs was used as the filler, while, those formed with starch showed a range from 10 to $600 \mathrm{~nm}$. The beads containing the micro-pores were called micro-porous beads.

\subsection{Immobilization of Cells in Micro-Porous Beads} Microorganisms were immobilized in the microporous beads by adding a known density of each organism into a beaker containing a sterilized solution of the sodium alginate $(2 \%)$, mixed with different concentrations (between 0.4 and $4.0 \%$ ) of the St, or Gs (Tables 1 and 2). A mixture of the three (sodium alginate, cell, and St or Gs) was dropped slowly into a gently stirred calcium chloride $(2 \%)$ solution. The droplets were solidified upon contact with calcium chloride due to cross-linkage between alginate and calcium chloride, thereby trapping the cells. On the other hand, the St or Gs was dissolved in calcium chloride and subsequently leached into the solution thereby creating micro-pores. The resulting gel beads were further incubated for $24 \mathrm{~h}$ in $\mathrm{CaCl}_{2} \cdot 2 \mathrm{H}_{2} \mathrm{O}$ solution to enhance cross-linking and stability of the beads. The micro-porous beads were recovered afterward and washed in a sterile distilled water to remove excess calcium, leaked, and un-entrapped cells as well as dissolved solutes before introduction into the fermentation flask. 


\subsection{Determination of Solubilization Time of the Gel} Beads

Solubilization of the beads was done using $0.2 \mathrm{M}$ citrate buffer. Ten of the calcium alginate gel beads were randomly selected and added to a $100 \mathrm{~mL}$ beaker containing $10 \mathrm{~mL}$ of the $0.2 \mathrm{M}$ citrate buffer and agitated at $70 \mathrm{rpm}$ by a magnetic stirrer. The buffer chelated the $\mathrm{Ca}^{2+}$ and disrupted the gel structure of the beads, leading to solubilization of the beads. The time taken for the beads to dissolve completely in the $10 \mathrm{~mL}$ of the buffer was recorded as the solubilization time. The effect of length of incubation time in calcium chloride on the solubilization time was determined by incubating the freshly prepared gel beads in $2 \%$ calcium chloride solution. Ten of the beads were taken at time intervals, suspended in $10 \mathrm{~mL}$ of sodium citrate buffer and the solubilization time was determined as already described. The effect of cultivation in YPG medium on the solubilization time was also evaluated. Yeast cells were immobilized in the normal and micro-porous beads and used to inoculate YPG medium in $500 \mathrm{~mL}$ Erlenmeyer flasks. The flasks were incubated on shaker incubator (70 rpm). Ten of the beads were taken at intervals and the solubilization time was determined.

\subsection{Determination of Immobilized Cell Density}

The total numbers of immobilized cells within the beads were determined by selecting 10 beads at random from the fermentation broth. The selected beads were dissolved in a $0.2 \mathrm{M}$ sodium citrate buffer at $\mathrm{pH} 6$. The dissolved beads were serially diluted and plated on a Potato Dextrose Agar (for $S$. cerevisiae) or Nutrient Agar (for B. subtilis) in Petri dishes. The plates were then incubated at $30{ }^{\circ} \mathrm{C}$ for $18-24 \mathrm{~h}$ and the numbers of colonies were counted.

\subsection{Evaluation of Cell Leakage and Growth in the Broth During Fermentation}

Cell leakage from the gel beads was evaluated by counting the number of cells in the culture broth. The number of cells in the broth was obtained by diluting the broth, plating on Potato Dextrose Agar (for $S$. cerevisiae) or Nutrient Agar (for B. subtilis), and was determined by counting the number of the formed colonies.

\subsection{Determination of Mechanical Strength of the Beads}

The physical stability of the beads was tested using an automated Instron Universal Tester, Model 3369 having the maximum capacity of $50,000 \mathrm{~N}$. The beads' diameter was measured using a Caliper and thereafter placed on the machine platform for strength measurement. The maximum compressive stress of the beads was estimated in mega Paschal (Mpa). The mechanical strengths of the micro-porous gel beads produced from alginate-starch mixture and the normal gel beads produced from sodium alginate alone (control) were compared after incubation of the beads in different concentrations of the $\mathrm{CaCl}_{2} \cdot 2 \mathrm{H}_{2} \mathrm{O}$ for 24 $\mathrm{h}$. The cell density in the beads used for mechanical strength determination was $1.0 \times 10^{5}$ cells/bead each for $S$. cerevisiae and $B$. subtilis while the bead diameter was $3 \mathrm{~mm}$.

\subsection{Statistical Analysis}

The data were statistically analyzed using a oneway Analysis of Variance (ANOVA), while the Least Significant Difference (LSD) was used to separate the means. Normal calcium alginate gel beads were used as the control beads. Results of the experiment are presented as averages of triplicate experiments \pm standard error of the mean.

\section{Results}

\subsection{Effect of Length of Incubation in Calcium Chloride} on Bead Solubilization Time

The control beads produced by gelling $2 \%(\mathrm{w} / \mathrm{v})$ sodium alginate in calcium chloride were compared to the microporous beads which were produced by gelling a mixture of $2 \%$ sodium alginate and granulated sugar (Gs) or starch (St) in calcium chloride. At zero incubation time (immediately after immobilization), both the control and Gs beads had the same solubilization time of 34 minutes, while the St beads had a solubilization time of 59 minutes. After $12 \mathrm{~h}$ of incubation in $\mathrm{CaCl}_{2}$ solution, the Gs and St gel beads dissolved totally after 50 and 66 minutes, respectively. In contrast, the solubilization time of the control beads was increased only slightly to 36 minutes. After $24 \mathrm{~h}$ of incubation in $\mathrm{CaCl}_{2}$ solution, the solubilization time for the control, Gs and St beads increased to 41, 66, and 93 minutes respectively. Further increase in curing time did not result in a significant increase in the solubilization time ( $p>0.05)$.

By varying the concentration of starch in the sodium alginate for production of the micro-porous beads (between 0.4 and $4 \%$ ) at constant concentration of sodium alginate (Fig. 1), the time that was taken for the micro-porous beads to dissolve was increased with increasing concentration of the starch up to a peak of 90 minutes which in turn coincided with a starch concentration of $2 \%$. Beyond this point, further increase in the starch concentration had no significant reduction in the solubilization time of the St beads. 

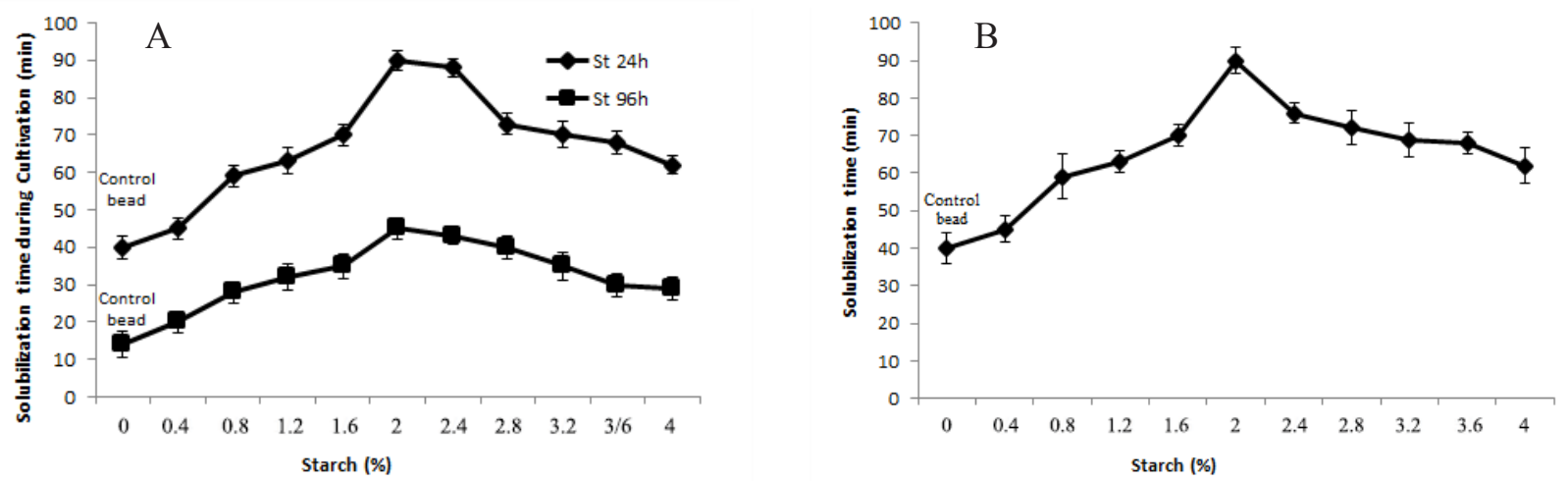

Figure 1. The effect of starch concentrations in the sodium alginate on the solubilization times of (A) calcium alginate gel beads immobilizing cells of Saccharomyces cerevisiae after cultivation for $24 \mathrm{~h}$ and $96 \mathrm{~h}$ and (B) micro porous gel beads without cells after curing in $\mathrm{CaCl}_{2}$ for $24 \mathrm{~h}$.

\subsection{Effects of Alginate: Starch Ratio and Cultivation Time on Solubilization Time}

The effects of the concentration of starch on the chemical stability of the micro-pourus beads immobilizing $S$. cerevisiae during cultivation in the YPG medium are shown in Figure 1A. For the control beads without cells, the solubilization time was decreased from 37 minutes to 14 minutes after $96 \mathrm{~h}$ of cultivation. In case of micro-porous beads without cells (Fig. 1B), the trend of solubilization time after $24 \mathrm{~h}$ cultivation was very similar to what was obtained in Figure 1B. The solubilization time increased with the increase in the concentration of starch until reaching a peak of 89 minutes at $2 \%$ starch concentration. Thereafter, a downward trend in solubilization time was observed with further increase in the starch concentration in the beads. When the beads immobilizing $S$. cerevisiae was cultivated for $96 \mathrm{~h}$ (Fig.1A), there was a significant reduction in the solubilization times $(p<0.05)$. For instance, with a starch concentration of $2 \%$, the solubilization time decreased from 89 minutes to 45 minutes after cultivation for $96 \mathrm{~h}$.

\subsection{Cell Growth in the Calcium Alginate Micro-Porous Gel Beads}

Table 1 summarizes the results of the growth of $S$. cerevisiae in the beads. The cell density in the control beads increased from an initial $4.0 \times 10^{6} \mathrm{cfu} / \mathrm{bead}$ to $6.9 \times 10^{7} \mathrm{cfu} / \mathrm{bead}$ after $72 \mathrm{~h}$ of cultivation. However, in the micro-porous beads prepared from a mixture of $2 \%$ sodium alginate and $0.4 \%$ starch, the cell density increased to a very high value of $1.2 \times 10^{8} \mathrm{cfu} / \mathrm{bead}$ after

Table 1. Effect of starch concentrations on the concentration of Saccharomyces cerevisiae inside the calcium alginate beads and in the culture broth after $72 \mathrm{~h}$ of cultivation in YPG medium.

\begin{tabular}{lccc}
\hline Starch Conc. (\%) & $\begin{array}{c}\text { Initial cell conc. } \\
\text { (cfu/bead) }\end{array}$ & $\begin{array}{c}\text { Cell conc. in the bead } \\
\text { after } \mathbf{7 2} \mathbf{~ h} \text { (cfu/bead) }\end{array}$ & $\begin{array}{c}\text { Cell conc. in the broth } \\
\text { after } \mathbf{7 2} \mathbf{~ h} \text { (cfu/bead) }\end{array}$ \\
\hline 0.4 & $3.8 \pm 0.03 \times 10^{6}$ & $1.2 \pm 0.03 \times 10^{8}$ & $2.3 \pm 0.02 \times 10^{5}$ \\
0.8 & $3.8 \pm 0.03 \times 10^{6}$ & $8.0 \pm 0.03 \times 10^{7}$ & $2.4 \pm 0.02 \times 10^{5}$ \\
1.2 & $3.8 \pm 0.03 \times 10^{6}$ & $7.7 \pm 0.04 \times 10^{7}$ & $2.4 \pm 0.01 \times 10^{5}$ \\
1.6 & $3.9 \pm 0.04 \times 10^{6}$ & $6.2 \pm 0.04 \times 10^{7}$ & $3.0 \pm 0.01 \times 10^{5}$ \\
2.0 & $4.0 \pm 0.03 \times 10^{6}$ & $6.1 \pm 0.04 \times 10^{7}$ & $3.7 \pm 0.01 \times 10^{5}$ \\
2.4 & $4.0 \pm 0.02 \times 10^{6}$ & $6.0 \pm 0.03 \times 10^{7}$ & $3.7 \pm 0.02 \times 10^{5}$ \\
2.8 & $3.9 \pm 0.03 \times 10^{6}$ & $5.7 \pm 0.05 \times 10^{7}$ & $4.0 \pm 0.01 \times 10^{5}$ \\
3.2 & $3.9 \pm 0.02 \times 10^{6}$ & $5.4 \pm 0.04 \times 10^{7}$ & $4.4 \pm 0.03 \times 10^{5}$ \\
3.6 & $4.0 \pm 0.02 \times 10^{6}$ & $5.0 \pm 0.03 \times 10^{7}$ & $4.5 \pm 0.02 \times 10^{5}$ \\
4.0 & $4.0 \pm 0.03 \times 10^{6}$ & $4.4 \pm 0.03 \times 10^{7}$ & $4.7 \pm 0.02 \times 10^{5}$ \\
Control & $4.0 \pm 0.03 \times 10^{6}$ & $6.9 \pm 0.04 \times 10^{7}$ & $3.5 \pm 0.03 \times 10^{5}$ \\
\hline
\end{tabular}

Control beads were prepared with $2 \%$ sodium alginate only. 
Table 2. Effect of starch concentrations on the concentration of Bacillus subtilis inside the calcium alginate beads and in the culture broth after $48 \mathrm{~h}$ of cultivation in nutrient broth.

\begin{tabular}{|c|c|c|c|}
\hline Starch Conc. $(\%)$ & $\begin{array}{c}\text { Initial cell conc } \\
(\mathrm{cfu} / \mathrm{bead})\end{array}$ & $\begin{array}{l}\text { Cell conc. in the bead } \\
\text { after } 48 \mathrm{~h} \text { (cfu/bead) }\end{array}$ & $\begin{array}{l}\text { Cell conc. in the broth } \\
\text { after } 48 \mathrm{~h} \text { (cfu/bead) }\end{array}$ \\
\hline 0.4 & $6.2 \pm 0.01 \times 10^{7}$ & $5.9 \pm 0.03 \times 10^{9}$ & $9.6 \pm 0.04 \times 10^{5}$ \\
\hline 0.8 & $6.2 \pm 0.01 \times 10^{7}$ & $5.3 \pm 0.04 \times 10^{9}$ & $9.7 \pm 0.01 \times 10^{5}$ \\
\hline 1.2 & $6.3 \pm 0.04 \times 10^{7}$ & $5.0 \pm 0.04 \times 10^{9}$ & $9.9 \pm 0.01 \times 10^{5}$ \\
\hline 1.6 & $6.2 \pm 0.03 \times 10^{7}$ & $4.7 \pm 0.05 \times 10^{9}$ & $1.1 \pm 0.04 \times 10^{6}$ \\
\hline 2.0 & $6.2 \pm 0.04 \times 10^{7}$ & $4.2 \pm 0.05 \times 10^{9}$ & $1.3 \pm 0.02 \times 10^{6}$ \\
\hline 2.4 & $6.2 \pm \times 0.0510^{7}$ & $4.0 \pm 0.05 \times 10^{9}$ & $1.4 \pm 0.04 \times 10^{6}$ \\
\hline 2.8 & $6.1 \pm 0.04 \times 10^{7}$ & $3.7 \pm 0.04 \times 10^{9}$ & $1.7 \pm 0.02 \times 10^{6}$ \\
\hline 3.2 & $6.1 \pm 0.01 \times 10^{7}$ & $3.5 \pm 0.03 \times 10^{9}$ & $1.8 \pm 0.02 \times 10^{6}$ \\
\hline 3.6 & $6.2 \pm 0.03 \times 10^{7}$ & $3.1 \pm 0.05 \times 10^{9}$ & $1.9 \pm 0.01 \times 10^{6}$ \\
\hline 4.0 & $6.0 \pm 0.02 \times 10^{7}$ & $3.0 \pm 0.03 \times 10^{9}$ & $1.9 \pm 0.03 \times 10^{6}$ \\
\hline Control & $6.2 \pm 0.02 \times 10^{7}$ & $4.1 \pm 0.01 \times 10^{9}$ & $9.9 \pm 0.03 \times 10^{5}$ \\
\hline
\end{tabular}

Control beads were prepared with $2 \%$ sodium alginate only.

$72 \mathrm{~h}$ of cultivation. The immobilized cell density was decreased with an increase in the starch concentration in the sodium alginate, but, even with $1.2 \%$ starch, cells still grew better in the micro-porous gel beads than in the normal gel beads $(p<0.05)$. Cell leakage (density of free cells in the broth) was lower in the cultures with micro-porous gel beads prepared with low starch concentrations. However, for the high porous beads, prepared with high starch concentration $(>1.2 \%$ starch), the cell growth inside the beads was lower, while cell leakage was higher than those of the control beads.

In case of immobilized Bacillus subtilis, the results obtained after $48 \mathrm{~h}$ of cultivation is summarized in Table 2. A comparatively higher $(p<0.05)$ density of cells were found in both the beads and the broth compared to the yeast cells. The cell density in the control bead was $4.1 \times 10^{9} \mathrm{cfu} / \mathrm{bead}$, while the cell density in the broth was $9.9 \times 10^{5}$ cfu. $\mathrm{mL}^{-1}$ after $48 \mathrm{~h}$ of cultivation. The cell density in the micro-porous gel beads prepared with low starch concentrations was significantly higher than the values obtained for the normal gel beads $(p<0.05)$. With a starch concentration of $0.4 \%$, the cell density in the beads was $5.6 \times 10^{9} \mathrm{cfu} /$ bead as against $4.1 \times 10^{9} \mathrm{cfu} / \mathrm{bead}$ in the normal gel beads. The immobilized cell density was decreased with an increased starch concentration (increase in the porosity of the beads), but even with $2 \%$ starch, the immobilized cell density was still higher than that of the control beads. In the highly porous beads (starch concentration higher than 2\%), the immobilized cell density decreased while the free cell density in the broth increased significantly. The micro-porous beads produced with the starch ranging in concentration from 3.2 to $4.0 \%$ had lower immobilized cells $\left(2.4 \times 10^{9}\right.$ to $\left.3.0 \times 10^{9} \mathrm{cfu} / \mathrm{bead}\right)$ and a higher cell leakage $\left(2.0 \times 10^{6}\right.$ to $2.3 \times 10^{6}$ cfu. $\left.\mathrm{mL}^{-1}\right)$ than that of control beads.

\subsection{Distribution of Cells in the Beads}

Figures 2A and 2B show the optical microscopic view (X400) of the distribution of Saccharomyces cerevisiae
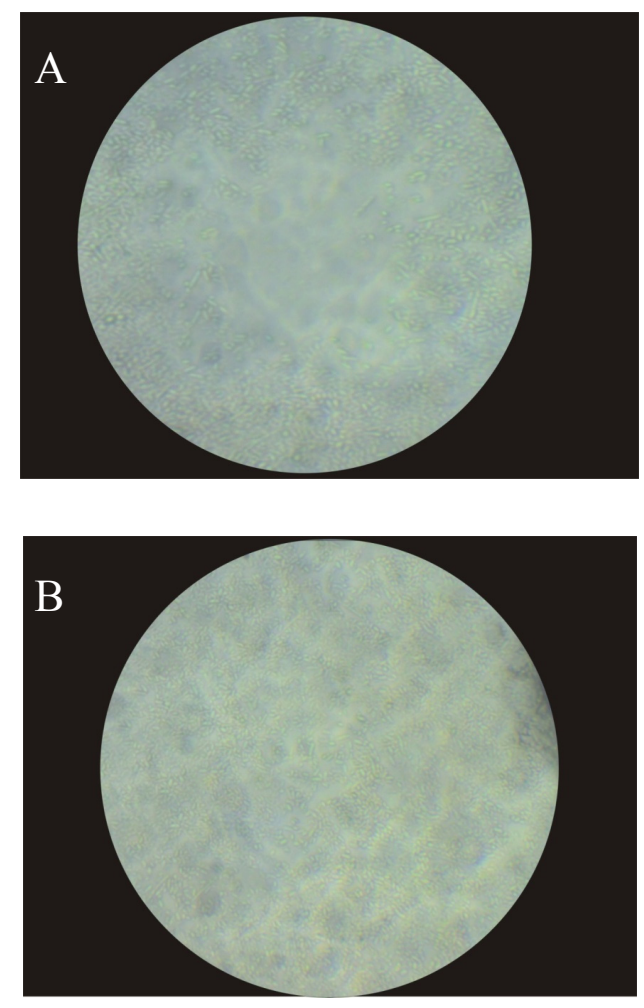

Figure 2. Light microscopic photograph (X400) showing the distribution of the Saccharomyces cerevisiae cells in a normal calcium alginate gel bead (A), and in a micro-porous calcium alginate gel bead (B). 
Table 3. Compressive (mechanical) strength of calcium alginate micro-porous gel beads (MPa) cured in different concentrations of $\mathrm{CaCl}_{2}$ during cultivation of Saccharomyces cerevisiae.

\begin{tabular}{lcc}
\hline Calcium chloride conc. (\%) & $\begin{array}{c}\text { Compressive strength after 24 h of } \\
\text { cultivation (Mpa) }\end{array}$ & $\begin{array}{c}\text { Compressive strength after 96 h of } \\
\text { cultivation (Mpa) }\end{array}$ \\
\hline $\mathbf{1 . 5}$ & $5.54 \pm 0.08$ & $5.52 \pm 0.06$ \\
$\mathbf{2 . 0}$ & $5.62 \pm 0.06$ & $5.55 \pm 0.08$ \\
& $(5.54 \pm 0.07)^{*}$ & $(5.40 \pm 0.08)^{*}$ \\
$\mathbf{2 . 5}$ & $5.67 \pm 0.07$ & $5.66 \pm 0.09$ \\
\hline
\end{tabular}

*Values in parenthesis are for the typical (control) calcium alginate beads.

cells in the normal and micro-porous beads. In the case of normal gel beads (Fig. 2A), the cells grew mainly within the periphery of the beads. However, as shown in Figure 2B, there was a uniform distribution of the cells in the micro-porous beads.

\subsection{Mechanical Strength of the Beads}

The results of the physical stability of the beads are presented in Table 3. The compressive strength of the micro-porous gel beads was increased with an increase in the $\mathrm{CaCl}_{2} \cdot 2 \mathrm{H}_{2} \mathrm{O}$ concentration, but decreased during cultivation. When the beads prepared with $2 \%$ calcium chloride were cultivated in the YPG medium for $96 \mathrm{~h}$, the compressive strength of the micro-porous gel beads showed a decrease to $5.55 \mathrm{Mpa}$ which was in contrast to the control beads that showed a decrease to $5.40 \mathrm{Mpa}$. It is important to note that the compressive strength of the micro-porous beads after $96 \mathrm{~h}$ of cultivation was even higher than that of the control beads after $24 \mathrm{~h}$ of cultivation.

\section{Discussion}

To the best of our knowledge, this is the first report on the production of micro-porous calcium alginate gel beads for immobilization of cells. Schoebitz et al., (10) produced beads from sodium alginate:starch mixture, but the aim was to protect the cells and the starch concentration was so high ( $47 \mathrm{~g}$ of starch in $3 \mathrm{~g}$ of sodium alginate) that it could not have leached out to create micro-pores. We have shown that micro-porous calcium alginate beads could easily be produced by mixing different concentrations of the starch or sugar with sodium alginate solution and dropping the mixture into calcium chloride solution.

As in the case of conventional calcium alginate beads (11), the stability of the micro-porous gel beads was increased by incubating (curing) in the calcium chloride solution after immobilization. This could be attributed to the formation of more cross-linkages and progressive accumulation of calcium in the beads (12). It is interesting to note that micro-porous beads were chemically and physically more stable than normal beads. This might be due to the better penetration of $\mathrm{CaCl}_{2}$ into the core of the beads, leading to a better cross-linkage between carboxyl groups in the alginate with the calcium ions from the chloride solution.

The results have also shown that both $S$. cerevisiae and $B$. subtilis grew better in the micro-porous gel beads than in the conventional calcium alginate gel beads. The micro-pores in the beads facilitate mass transfer and thus support a better growth of the cells. The micro-porous beads can potentially be used for immobilization of other cells (13) or for vitamin and drug delivery (14).

\section{Conclusion}

The concept and method of producing micro-porous calcium alginate gel beads are described for the first time. Micro-porous beads can easily be produced by mixing either granulated sugar or starch with sodium alginate before dropping into calcium chloride solution. Altogether, micro-porous gel beads were chemically and physically more stable and had higher cell holding capacity than the normal gel beads. However, when the concentration of the fillers was too high, both the stability and cell holding capacity of the beads were decreased. The optimum porosity for the cell growth would depend on the size and growth characteristics of the immobilized cells, but for $S$. cerevisiae and $B$. suntilis the micro-porous beads prepared from a mixture of sodium alginate and $0.4 \%$ starch were the best.

\section{References}

1. Lakshmi V, Das D, Das N. Biodegradation of caffeine by the yeast Trichosporon asahii immobilized in single and hybrid matrices. Indian J Chem Technol. 2013;20:195-201. doi: 10.5958/0974-360x2016.00430.3

2. Martins SCS, Martins CM, Fiuza LMCG, Santaella ST. Immobilization of microbial cells: A promising tool fort 
reatment of toxic pollutants in industrial wastewater. Afri $J$ Biotechnol. 2013;12(28):4412-4418. doi: 10.5897/AJB12.2677

3. Tanaka H, Irie S, Ochi H. A novel immobilization method for prevention of cell leakage from the gel matrix. $J$ Ferment Biotechnol. 1989;68:216-219. doi:10.1016/0922$338 x(89) 901414$

4. Tartakovsky B, Guiot SR, Sheintuch M. Modeling and analysis of co-immobilized aerobic/anaerobic mixed cultures. Biotechnol Progress. 2008;14:672-679. doi: 10.1021/bp9800687

5. Ogbonna JC, Matsumura M, Kataoka H. Effective oxygenation of immobilized cells through reduction in bead diameter. Process Biochem. 1991;26:109-121. doi:10/1016/00329592(91980025-k

6. Kregiel D, Berlowska J, Ambroziak W. Growth and metabolic activity of conventional and non-conventional yeasts immobilized in foamed alginate, Enzy Microbial Technol. doi:10.1016/j.enzmictec.2013.05.010.

7. Wilkowska A, Kregiel D, Guneser O, Yuceer YK. Growth and by-product profiles of Kluyveromyces marxianus cells immobilized in foamed alginate. Yeast. 2014 doi:10.1002/ yea3044.

8. Ogbonna JC, Pham CB, Matsumura M, Kataoka H. Evaluation of some gelling agents for immobilization of aerobic microbial cells in alginate and carrageenan gel beads. Biotechnol. Tech. 1989;3:421-424. doi:10.1007/BF01875012
9. Kuriyama H, Seiko T, Kobayashi H, Sonoda Y. Continuous ethanol fermentation with cell recycling using flocculating yeast. J Ferment Technol. 1985; 63:159-165. doi:10.1007/ BF00128287

10. Schoebitz M, Simonin H, and Poncelet D. Starch filler and osmoprotectants improve the survival of rhizobacteria in dried alginate beads. J Microencapsul. 2012;29(6):532-538. doi:10.3 109/02652048.2012.665090.

11. Ogbonna JC, Amano Y, Nakamura K. Elucidation of optimum conditions for immobilization of viable cells by using calcium alginate. J Ferment Bioeng. 1989;67:92-96. doi:10.1016/0922$338 x(89) 90186-4$

12. Fazilah A, Maizura M, Abdkarim A, Bhupinder K, Rajeev B, Uthumporn U, Chew SH. Physical and mechanical properties of sago starch-alginate film incorporated with calcium chloride. Inter Food Res J. 2011; 18:1027-1033.

13. Kattimani L, Amena S, Nandareddy V, Mujugong P. Immobilization of Streptomyces gulbargensis in polyurethane foam: A promising technique for L-asparaginase production. Iranian J Biotechnol. 2009;7(4):199-204.

14. Rashidi L, Vasheghani-Farahani E, Rostami K, Gangi F, Fallahpour M. Mesoporous silica nanoparticles as nanocarrier for delivery of vitamin C. Iranian J Biotechnol. 2013;11(4):209213. doi: $10.5812 /$ ijb. 14279 . 